\title{
Desenvolvimento de Software para Organizações sociais
}

\author{
Leonardo Gargano ${ }^{1}$, Barbara Ramos ${ }^{2}$, Marcelo Fornazin ${ }^{2}$ \\ ${ }^{1}$ Departamento de Ciência da Computação - Universidade Federal do Rio de Janeiro \\ (UFRJ) \\ Caixa-postal 68530 - Rio de Janeiro - RJ - Brasil \\ ${ }^{2}$ Instituto de Computação - Universidade Federal Fluminense (UFF) \\ Niterói - RJ - Brasil \\ leogargano@gmail.com, bramos@id.uff.br, fornazin@ic.uff.br
}

\begin{abstract}
The software development process is a complex activity that involves uncertainties and challenges. These uncertainties and challenges become more potent as we seek to build systems and technologies for the third sector, an area that have different practices and values of business management. Currently, Information Technology (IT) field does not hold debates about the characteristics of the organization frequently. This article presents reflections on a construction in progress of a software used by social organizations
\end{abstract}

Resumo. O processo de desenvolvimento de software é uma atividade complexa que envolve incertezas e desafios. Essas incertezas e desafios potencializam-se quando buscamos construir sistemas e tecnologias para o terceiro setor que possuem práticas e valores diferentes da gestão empresarial. Atualmente, a área de Tecnologia da Informação (TI) não realiza debates relativos às características das organizações sociais com frequência. Este artigo apresenta reflexões sobre a construção em andamento de softwares utilizado por movimentos sociais.

\section{Introdução}

As práticas de gestão empresarial são amplamente empregadas em diversos setores da sociedade, entre eles a gestão de organizações sociais, como por exemplo, entidades filantrópicas, organizações não governamentais e movimentos sociais. Entretanto, autores como Tenório (1998) e Ciborra (2005) defendem que a gestão empresarial não é universal e possui limites quando aplicada aos setores público e social.

A Engenharia de Software (ES) está reconhecendo a importância de conceitos externos à Ciência da Computação como psicologia e ciências sociais. Neste sentido, há autores, como Lenberg (2015) que já percebem que para o desenvolvimento de software é necessário um esforço coletivo, contemplando e abrangendo questões sociais, cognitivas, culturais, políticas e organizacionais.

Ainda assim, muito pouco do debate sobre as características das organizações sociais é feito na área de Sistemas de Informação (SI) e, na maioria das vezes, busca-se construir sistemas e tecnologias para o terceiro setor inspirados nas práticas da gestão empresarial, com absorção de práticas desenvolvidas no exterior, que nem sempre são 
aplicáveis às estruturas físicas e culturais brasileiras (Araujo et al. 2005) e desconsiderando-se os valores inerentes às organizações sociais.

Com objetivo de contribuir para o preenchimento da lacuna de conhecimento sobre SI nas organizações sociais, este artigo apresenta os principais aspectos da construção em andamento de SIs para projetos sociais utilizando a metodologia ágil Scrum e expõe uma reflexão sobre SI neste ambiente.

\section{Gestão Social}

Nas últimas décadas foi observado um grande crescimento nas aplicações computacionais, assim o software está se tornando parte vital de serviços e produtos (Guerra et. al 2005), a qual evidencia a importância dos sistemas na competição com concorrentes e na geração de valor para empresas. De acordo com Turban et al. (2013), para se manterem em competição as empresas precisam atualizar, desenvolver e/ou implantar novos SI. A perspectiva empresarial é relevante para uma boa parte dos ambientes em que os SI são utilizados e desenvolvidos.

Entretanto, um considerável número de organizações não compartilham dos valores e do modo de trabalho empresarial, como por exemplo as organizações não governamentais e os movimentos sociais. Estas organizações muitas vezes operam em um ambiente não competitivo e lidam com cidadãos ou grupos sociais. Desta forma, as teorias de SI originalmente desenvolvidas nos ambientes empresariais, embora possam ser replicadas para os cenários sociais, possuem certas limitações e efetividade questionável.

Já que a gestão empresarial possui limites quando aplicada às organizações sociais, existem propostas alternativas de gestão, como citado por Tenório (1998) a gestão social que em primeiro lugar, não tem orientação para finalidades econômicas, e desse modo há uma busca por soluções alternativas às técnicas e métodos gerenciais da administração empresarial.

A gestão social, diferente da gestão empresarial, propõe uma maior participação no gerenciamento, no qual diferentes sujeitos sociais exercem o processo decisório (Tenório 1998). As técnicas de gestão social, são úteis para organizações do chamado terceiro setor, sendo aplicadas, entre outros, às associações voluntárias, instituições filantrópicas, movimentos sociais e organizações não governamentais. Neste contexto, surge uma oportunidade para se pensar o desenvolvimento e uso de SI nessas organizações a partir dos pressupostos de uma gestão social.

\section{Aspectos Não-Técnicos}

Não é difícil encontrar usuários de software que tenham alguma dificuldade em utilizalo em seus aspectos básicos. Silva et al. (2005), atribuem essas dificuldades à inadequação dos procedimentos ou resultados computacionais às necessidades reais das pessoas que interagem com o software.

É comum ao desenvolver SI atribuir todo o sucesso as características técnicas, enquanto as "resistências" e fracassos ficarem por conta dos fatores não-técnicos (Cukierman et al. 2007). Os aspetos não-técnicos envolvem fatores humanos, organizacionais, éticos, políticos, sociais entre outros (Evaristo, 2000; Herbsleb et. al., 
1999; Herbsleb et. al., 2001; Layzell et. al, 2000; Kiel, 2003, Prikladnicki et. al 2005). Esses aspectos dizem respeito as entidades participantes da ES que afetam a forma como este é construído e projetado.

De acordo com autores como Layzell et. al (2000) e Prikladnicki (2005) a qualidade técnica de um software pode ser comprometida quando são desconsiderados os aspectos não-técnicos. As atividades técnicas podem ficar comprometidas, quando os desenvolvedores tem dificuldade em lidar com os aspectos não-técnicos do processo.

É consenso que o processo de desenvolvimento de software é uma atividade complexa que envolve dificuldades e desafios, desde os aspectos técnicos até os aspectos não-técnicos (Herbsleb et al. 2001). O desenvolvimento de software não é uma ciência exata que contêm leis ou regras pré-estabelecidas (Dias Jr et. al. 2018), é algo complexo, abstrato e facilmente modificado.

\section{Desenvolvimento de Software}

O trabalho em desenvolvimento é realizado no GESIGS - Grupo de Estudos em Sistemas de Informação com foco em Gestão Social - UFF que hoje é responsável pelo desenvolvimento de dois softwares voltados para movimentos sociais: O Dicionário de Favelas Marielle Franco e o Mulheres em Rede.

O Dicionário de Favelas Marielle Franco, é uma plataforma virtual para produção coletiva e busca suprir uma lacuna do conhecimento transdisciplinar que é o estudo de favelas, reunindo o conhecimento produzido em vários eixos temáticos (condições socioeconômicas, políticas públicas, cultura, sociabilidade entre outros).

O Mulheres em Rede é um portal para criação de um ambiente de formação, assessoria e troca virtual que promova o encontro criativo entre as empreendedoras, que possui palestras, blog e cursos.

Visando contemplar os aspectos não-técnicos e as peculiaridades das organizações sociais, a metodologia escolhida para o desenvolvimento dos dois softwares citados foi o método ágil Scrum, por possibilitar uma maior adaptação as mudanças, propor um desenvolvimento rápido aumentando o foco nas pessoas e não nos processos (Rubim, 2017). Destaca-se que o Manifesto Ágil ${ }^{1}$ de 2001, estabeleceu algumas premissas para o desenvolvimento ágil: indivíduos e interações mais que processos e ferramentas, software em funcionamento mais que documentação abrangente, colaboração com o cliente mais que negociação de contratos responder a mudanças mais que seguir um plano, sendo nestes aspectos a metodologia escolhida como ideal para os desenvolvimentos em questão.

Para o "funcionamento" do Scrum é essencial ter uma boa comunicação e integração da equipe. No processo de construção dos softwares a equipe de desenvolvimento buscou a participação ativa das instituições participantes ${ }^{2}$. Em

\footnotetext{
${ }^{1}$ http://agilemanifesto.org/

2 Participam do projeto Dicionário de Favelas Marielle Franco as seguintes instituições: UERJ, UFF, FGV EBAPE-PEEP, FIOCRUZ, UFRJ, Coletivo de Estudos sobre Violência e Sociabilidade, Instituto de Pesquisa e Planejamento Urbano e Regional, Instituto Raízes em Movimento, Centro de Estudos e Ações
} 
reuniões periódicas, as instituições participam das decisões de projeto, desde layout a forma de cadastro de novos usuários. Em algumas ocasiões a equipe de desenvolvimento faz ponderações quanto a viabilidade técnica de alguns pedidos.

É importante ressaltar que algumas características inerentes as organizações sociais como diferentes atores sociais participando do processo decisório afetaram a velocidade do desenvolvimento. Entretanto, como a construção dos SI para área social não segue os objetivos empresariais, tais como retorno financeiro ou vantagem competitiva, mas busca promover a colaboração e o valor público compartilhado do conhecimento produzido por diversos sujeitos sociais. A "demora no desenvolvimento" não interfere no processo de construção do software, ao contrário, as diversas interações bem gerenciadas contribuem positivamente para o desenvolvimento de software realmente aplicável ao ambiente em questão.

\section{Conclusão e Trabalhos Futuros}

Neste artigo, procuramos apresentar algumas reflexões sobre o processo de construção de SI na área social, tentando focar nos usuários, buscando melhorar a qualidade do desenvolvimento de software.

Durante as etapas já percorridas da construção dos softwares, podemos concluir que, ao empregar o Scrum em um projeto de cunho social, não se buscou atingir objetivos pré-estabelecidos, mas construir coletivamente os objetivos do projeto, bem como conhecimentos, à medida que o projeto, se desenvolve ou seja, neste projeto mais importante do que seus objetivos iniciais, é o caminho trilhado para a construção do SI, neste ambiente, ainda pouco explorado.

Assim, observa-se que a o Scrum é uma boa prática para construção de SI em ambientes cujo conhecimento da equipe técnica não é pleno no início do projeto. A interação proporcionada pelo Scrum provê agilidade e permite que o projeto seja adaptado à medida que a equipe técnica absorve conhecimento sobre o ambiente da organização social.

Para trabalhos futuros, esperamos adotar estudos experimentais como estratégia para coleção e análise de dados, podendo ser útil para construir evidências a respeito de benefícios, funcionalidades e difículdades na construção de tecnologias para o terceiro setor. Bem como um estudo de caso detalhando todo o processo de desenvolvimento e investigar processos de comunicação com stakeholders, bem como compreender melhor quais motivações levam os usuários, muitos deles voluntários, a participarem na área social, convergindo sempre as possibilidades de contribuições e interações positivas de SI para os aspectos e ambientes analisados.

\section{Referências}

Rubin, K. S. (2017) Scrum Essencial - Um Guia Prático Para o Mais Popular processo Ágil, Alta Books, Rio de Janeiro

Culturais e de Cidadania, Grupo ECO Santa Marta, Núcleo Piratininga de Comunicação, Observatório de Favelas e Redes da Maré 
Ciborra, C. (2005) "Interpreting e-government and development: Efficiency, transparency or governance at a distance?”. Information Technology \& People, p. 260-279.

Tenorio, F. (1998) "Gestão social: uma perspectiva conceitual”, Revista de Administração Pública, p. 7-32.

Lenberg, P.; Feldt, R.; Wallgren, L. G.. (2015) "Behavioral software engineering: A definition and systematic literature review". Journalof Systems and software, v. 107, p. 15-37.

Turban, E. e Volonino, L. (2013) Tecnologia da Informação para Gestão: Em Busca de um Melhor Desempenho Estratégico e Operacional. Bookman, Porto Alegre.

Guerra, A.; Capovilla, I. e Thienne, R. (2005). "O processo de software e seus atores sociais”. In: I WOSES, Rio de Janeiro, RJ, Brasil

Evaristo, Roberto; Scudder, Richard. (2000) "Geographically distributed project teams: a dimensional analysis”. In: HICSS, Havaí. Proceedings... EUA, p. 1-15.

Herbsleb, J. D., Grinter, R. E. (1999) "Splitting the Organization and Integrating the Code: Conway's Law Revisited.” In: Proc. 21th International Conference on Software Engineering (ICSE), Los Angeles, CA, EUA, pp. 85-95.

Layzell, P., Breneton, O. P., French, A. (2000) "Supporting Collaboration in Distributed Software Engineering Teams". In: Proceedings of the Seventh Asia-Pacific Software Engineering Conference.

Herbsleb, J. D., Moitra, D. (2001) "Guest Editors' Introduction: Global Software Development”, IEEE Software, vol. 18, no. 2, March/April, pp. 16-20.

Kiel, L. (2003) "Experiences in Distributed Development: A Case Study". In: Workshop on Global Software Development at ICSE, Oregon, EUA, 4p.

Prikladnicki, R. e Audy, J.L (2005) "Os Aspectos Não-Técnicos Intervenientes no Desenvolvimento Distribuído de Software”. In: I WOSES, pp 45-55.

Silva, A.L e Lima, F. (2005). "Análise de Requisitos de Software e Análise da Atividade de Trabalho". In: I WOSES, pp 31-44

Araujo, R. e Barros M. (2005). "O Olhar Sociotécnico da UNIRIO sobre a Engenharia de Software”. In: I WOSES, pp 15-23

Teixeira, C.A.N. e Cukierman, H.L. (2007). "Por que Falham os Projetos de Implanta ção de Processos de Software?”. In: III WOSES, pp 1-12.

Dias Jr, J.J.L. e Da Cunha J.A.O.G. (2018). “As competências para atuação na fronteira do conhecimento entre a engenharia de software e as ciências sociais: um ensaio teórico preliminar". In: III WASHES, pp 62-66 